\title{
In Memoriam: Professor Yoshiaki Deguchi (1929-2015)
}

Published online: 27 February 2016

(C) Japanese Society of Fisheries Science 2016

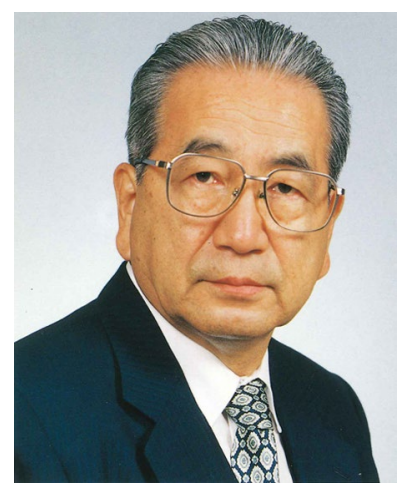

Professor Yoshiaki Deguchi, an Honorary Member of the Japanese Society of Fisheries Science, passed away at the age of 86 on 11 December 2015.

Professor Deguchi was born on 31 March 1929 in Tokyo. He graduated from the Department of Fisheries, College of Agriculture (currently the Department of Marine Science and Resources, College of Bioresource Sciences), Nihon University, in March 1952. In April 1953, he became a Research Associate at Nihon University. He was promoted to a Lecturer in 1959 and an Associate Professor in 1963. In 1974 he became a full Professor and managed the Laboratory of Aquaculture for 25 long years.

After holding many significant university positions and engaging in multiple activities, including Chairperson of the Department of Fisheries, Chairperson of the Course in Fisheries, Graduate School of Agriculture, Director of Marine Research Centers at Yokosuka and Shimoda of the College of Agriculture and Veterinary Medicine, Vice Dean of the College of Bioresource Sciences, and a member of the University Council, he retired from Nihon University in March 1999. During his university life, he supervised and trained a large number of Japanese and international students who are active in many fields.

Although Professor Deguchi studied many fields in aquaculture, his major area of research was focused on environmental science in aquaculture. Professor Deguchi published many scientific papers in Fisheries Science and Nippon Suisan Gakkaishi. He also made many presentations at the Symposium of the Japanese Society of Fisheries Science (JSFS). The content of these symposia have been published in the series of Fisheries Science, such as "Freshwater Fish Culture and Water Supply", "Live Fish Transportation", "Microbiological Aspects in Aquaculture", "Recent Advances in Tetrodotoxin Research", "Seed Production of Decapod Crustaceans", "Price Formation and Quality Control of Mariculture Products" and "Recent Advances in Fisheries Science".

Professor Deguchi also contributed extensively to the Japanese Society of Fisheries Science, serving as a member of the Board of Directors for 16 years. He also served on many committees, including the JSFS Awards Committee, the Symposia Planning Committee, and the Fisheries Environmental Conservation Committee.

In 2009, he received The Order of the Sacred Treasure, Gold Rays with Neck Ribbon.

Professor Deguchi educated and inspired many young people with his profound knowledge, noble-mindedness, and warm personality. We therefore express our deep condolences to the family of Professor Yoshiaki Deguchi and also express our gratitude for his achievements in research and education.

Haruo Sugita Professor, Nihon University 